\title{
Direct, Moderating and Mediating Effects of Market Orientation on the Performance of Airports in Europe's Peripheral Areas
}

\author{
Nigel Halpern \\ Romano Pagliari
}

\begin{abstract}
As a consequence of deregulation in the airline industry, market forces rather than public service considerations increasingly dictate routes serving airports in Europe's peripheral areas. The new market advocates market-driven management practices as a means of satisfying airline customers and implies that airports that adopt a more market-orientated approach than their rivals will perform better. This study investigates the relationship between market orientation and the performance of airports in Europe's peripheral areas. The research strategy was implemented using a questionnaire-based survey that was sent by email to managers at 214 airports. Usable responses from 84 airports were received and analysed. The findings demonstrate that market orientation has a significant and positive effect on performance, which is moderated by high levels of market turbulence and a focus on developing leisure services. The findings also demonstrate that the relationship between market orientation and performance is mediated by innovative marketing practices. The paper concludes with some implications for airport managers and recommendations for future research. doi:10.1300/J073v24n01_04 [Article copies available for a fee from The Haworth Document Delivery Service: 1-800-HAWORTH. E-mail address: <docdelivery@haworthpress.com> Website: $<$ http://www.HaworthPress.com> ( 2008 by The Haworth Press. All rights reserved.]
\end{abstract}

KEYWORDS. Market orientation, performance, airports, Europe's peripheral areas

\section{BACKGROUND}

The deregulation of European air transport markets was not complete until April 1997. Before deregulation, routes serving Europe's peripheral areas (EPAs) were somewhat protected because in exchange for monopoly rights on dense and profitable routes, national airlines or their subsidiaries would serve lightly populated and unprofitable routes such as those serving EPAs. However, "one of the consequences of deregulation has been the elimination of cross subsidy from loss-making domestic services and its replacement with direct subvention" (Williams, 2002, p. 135), which is implemented through the Public Service Obligation (PSO) programme.

The intention of the PSO programme is to support routes that are socially and economically necessary and cannot be provided on a commercial basis. However, the application and use of PSOs is at the discretion of member states and because of this, major inconsistencies exist in the approach and commitment to

Nigel Halpern is Associate Professor, Norwegian School of SCM \& Logistics, Molde University College, Postboks 2110, 6402 Molde, Norway (E-mail: nigel.halpern@ @imolde.no). Romano Pagliari is Lecturer, Department of Air Transport, Cranfield University, College Road, Cranfield, Bedfordshire MK43 0AL, UK (E-mail: r.pagliari@cranfield.ac.uk).

Journal of Travel \& Tourism Marketing, Vol. 24(1) 2008

Available online at http://jttm.haworthpress.com

(C) 2008 by The Haworth Press. All rights reserved. doi:10.1300/J073v24n01_04 
PSOs across Europe (Williams \& Pagliari, 2004). This means that routes serving EPAs are increasingly dictated by market forces rather than public service considerations.

The consequences of deregulation offer both threats and opportunities to airports in EPAs because despite being threatened by the loss or reduction of traditional services that are no longer commercially viable, airports also face opportunities to attract new services that were previously constrained by regulatory barriers that restricted an airlines choice of routes, frequency, capacity and pricing. The threats and opportunities are accentuated by the fact that the key asset of an airline is its aircraft and unlike airport infrastructure; aircraft are mobile and can be transferred to alternative routes if desired. Airlines also have multiple choices in terms of the number of airports that they can fly to/from.

The new market advocates market-driven management practices as a means of satisfying airline customers, which in marketing terminology implies that airports must have a market orientation. The new market also implies that airports that adopt a more market-orientated approach than their rivals will perform better.

When considering anecdotal evidence (e.g., Carrara, 2005), it is clear to see that some airports in EPAs have developed market orientated management practices as a means of satisfying airline customers. However, little has been done to develop a consistent measure of market orientation at airports or to develop a better understanding of how market orientation can affect the performance of airports. Empirical evidence on airport market orientation is limited to a study by Advani and Borins (2001) that used market orientation as an indicator of service quality and found that privatisation positively affects market orientation. However, their study did not investigate the link between market orientation and airport performance. Despite a growing body of literature on market orientation, no further research has been conducted on airports.

In light of the gap in literature, this study investigates the relationship between market orientation and the performance of airports in EPAs. In terms of the structure of this paper, the following section provides the theoretical context to this study, then the research methodol- ogy will be described, then an empirical analysis of the findings will be presented before concluding with a discussion of the main findings, implications for airport managers, and recommendations for future research.

\section{THEORY}

\section{Relationship Between Market Orientation and Performance}

Market orientation contrasts the philosophical value of the marketing concept with its implementation and conceptualisations of market orientation have been derived from two complementary perspectives; behavioural and cultural. The behavioural perspective concentrates on organisational activities related to the generation, dissemination and response to market intelligence (e.g., Kohli \& Jaworski, 1990) whilst the cultural perspective concentrates on organisational values such as customer orientation, competitor orientation and inter-functional coordination (e.g., Deshpandé, Farley, \& Webster, 1993; Narver \& Slater, 1990). Despite their differences, both perspectives work on the assumption that a market orientated company is likely to have superior market sensing and customer linking capabilities that are likely to result in superior performance (Day, 1994).

When investigating the effect of market orientation on performance, studies tend to investigate one or a number of the following effects:

- direct effect (i.e., 'if' market orientation has an effect on performance);

- moderating effect (i.e., 'when' market orientation has an effect on performance); and,

- mediating effect (i.e., 'how' market orientation has an effect on performance).

\section{Direct Effect}

This study is concerned with the effect that market orientation has on airport marketing performance (i.e., the attraction of new services and the growth and retention of existing services). This is as opposed to airport economic or operational performance. Previous studies have investigated the direct effect that market 
orientation has on marketing performance and suggest that the effect is significant and positive (e.g., Hooley et al., 2003; Sin, Tse, Heung, \& Yim, 2005).

It is unlikely that market orientation would have had an effect on the marketing performance of airports in EPAs during the regulated era because marketing performance would have been largely determined by government decisions. Deregulation has meant that airlines are freer to choose where they fly to/from and the decisions of airlines are increasingly based upon commercial (as opposed to public) considerations (Graham, 2003). In the deregulated environment, the assumption is that airports that are more market orientated are likely to perform better than those that are less market orientated because their superior market sensing and customer linking capabilities are likely to facilitate a superior relationship with existing or potential customers. Therefore, the hypothesis is as follows:

H1. The greater the market orientation of an airport, the greater its performance.

\section{Moderating Effect}

Previous studies have found that environmental factors such as market turbulence and competitive intensity strengthen the relationship between market orientation and performance (e.g., Harris, 2001; Kim, 2003).

Market turbulence is characterised by the rate of change in customers and their needs and preferences (Kohli \& Jaworski, 1990). In turbulent markets, it is likely that airports will benefit from being market orientated because they will be able to understand and respond to changes in the needs and preferences of existing or potential airline customers. Therefore, the hypothesis is as follows:

H2. The greater the market turbulence, the stronger the relationship between market orientation and airport performance.

Competitive intensity is characterised by an environment in which customers have multiple choices (Kohli \& Jaworski, 1990). In an environment where airlines have multiple choices, market orientation is expected to support the competitive advantage of an airport and encourage superior performance. This is because airports that fail to satisfy airline needs and preferences are more likely to lose out to competitors that can. Therefore, the hypothesis is as follows:

H3. The greater the competitive intensity, the stronger the relationship between market orientation and airport performance.

The ability for strategic focus to moderate the relationship between market orientation and performance has been recognised in previous studies (e.g., Matsuno \& Mentzer, 2000; $\mathrm{Wu}, 2004)$. This study will test the moderating effect of an airports strategic focus in terms of whether it is focused on developing public (as opposed to commercial) services and leisure (as opposed to traditional) services.

The relationship between market orientation and performance is likely to be weaker at airports that are seeking to develop public services because routes serving such airports are likely to be heavily subsidised and determined by public (as opposed to commercial) considerations. Under these circumstances, there is little incentive for an airport to be market orientated and it is likely that airports with low levels of market orientation can still perform well. Therefore, the hypothesis is as follows:

H4. The relationship between market orientation and airport performance is weaker at airports that focus on developing public services as opposed to commercial services.

Kealey (2004) distinguishes between two different types of passenger service; traditional services such as those that are offered by traditional mainline or regional carriers and leisure services such as those that are offered by charter, low-cost or niche regional carriers. Leisure services are highly elastic as they usually serve point-to-point routes and can easily transfer to different routes if existing routes are not commercially viable. This is in comparison to traditional services that tend to operate hub and spoke networks and may therefore be more in- 
clined to serve routes that are less commercially viable or are supported by subsidies in order to improve their network coverage. The highly elastic nature of leisure services suggests that the relationship between market orientation and performance will be stronger at airports that are seeking to develop leisure services compared to those that are seeking to develop traditional services. Therefore, the hypothesis is as follows:

H5. The relationship between market orientation and airport performance is stronger at airports that focus on developing leisure services as opposed to traditional services.

Matsuno, Mentzer, and Rentz (2005) suggest that market-level factors such as demand and supply should be taken into account when considering the factors that moderate the relationship between market orientation and performance.

Narver and Slater (1990) have studied the effect of demand and found that market orientation is less important in an environment where there are strong market opportunities. This is because market growth and potential acts as a disincentive to be market orientated. However, this study proposes that the opposite will be the case at airports. This is because airlines are more inclined to choose airports that can actually demonstrate strong market opportunities (Graham, 2003) and this can be achieved by having a strong market orientation. Therefore, the hypothesis is as follows:

H6. The greater the market opportunities, the greater the relationship between market orientation and airport performance.

As a consequence of their peripheral location, some airports in EPA's are likely to be constrained by supply factors such as limited infrastructure (e.g., inadequate runway, lighting or terminal capacity) or harsh operating conditions (e.g., operating limits, obstacles or frequent adverse weather). Airports that suffer from such constraints may not be in a position to gain from any market opportunities and this means that performance is impeded, irrespective of whether or not the airport is market orientated. Therefore, the hypothesis is as follows:

H7. The more constrained the airport, the weaker the relationship between market orientation and airport performance.

Whilst an understanding of the factors that moderate the relationship between market orientation and performance is of use to airport managers, it does not provide them with an understanding of the management practices that can influence the relationship and this is why an understanding of the mediating effect is so important.

\section{Mediating Effect}

Innovation is increasingly recognised for its mediating effect on the relationship between market orientation and performance. One of the earliest studies to recognise the importance of innovation was produced by Slater and Narver (1994). Their study proposed that innovation could be one of the core value-creating capabilities that mediate the relationship between market orientation and performance. In this instance the assumption is that companies with a superior market orientation will have superior market sensing and customer linking capabilities and should therefore be in a position to better understand the needs of their target markets and provide superior value through innovation. In this context, innovations are implemented as a result of market orientation as the medium of choice for achieving company performance.

The proposition by Slater and Narver (1994) was purely conceptual and it wasn't until Han, Kim, and Srivastava (1998) that an empirical study was conducted on the mediating effect of innovation. Their study found that technical and administrative innovations have a significant and positive mediating effect of on the relationship between market orientation and performance. Subsequent studies have tested different aspects of innovation but confirm its significant and positive mediating effect (e.g., see Agarwal, Erramilli, \& Dev, 2003).

It is very difficult to be innovative with the airport product, especially with core elements such as the ability for aircraft to land and take off. However, innovations can be implemented 
by airports within the context of airport marketing innovations (e.g., see Halpern, 2006), which can be achieved by developing new or modified products/services, brand strategies, pricing and incentive schemes, distribution channels, advertising and promotional campaigns, and management processes.

Airport marketing innovations are an appropriate means of improving airport marketing performance and are expected to have a positive mediating effect on the relationship between market orientation and performance. Therefore, the hypothesis is as follows:

H8. The greater the level of airport marketing innovation, the stronger the relationship between market orientation and airport performance.

In addition to investigating the mediating role of innovation on the relationship between market orientation and performance, this study will test the moderating effect of environmental support on the relationship between innovation and performance. The assumption here is that "innovation is an important source of competitive advantage in markets where customer preferences are changing rapidly, where competition is intense, where production lifecycles are shortening and maturing, and/or where differentiation is limited" (Gray, Matear, \& Matheson, 2000, p. 150). This quote implies that the relationship between innovation and performance will be at its strongest when environmental conditions are most supportive (i.e., when an airport operates in an innovation-friendly environment). Therefore, the hypothesis is as follows:

H9. Environmental support strengthens the relationship between marketing innovations and airport performance.

\section{METHOD}

Ten variables were needed in order to test the hypotheses and each variable was created using propositions on a survey. Airport managers were asked to respond to each proposition on a 5-point Likert scale with responses ranging from strongly agree, tend to agree, neutral, tend to disagree and strongly disagree. The propositions used to create the performance variable used responses ranging from much better, better, same, worse and much worse because respondents were asked to compare the performance of their airport to that of similar or competing airports. The marketing innovations variable was created using a 4-point Likert scale because there is no opportunity for a neutral response. Instead, airports have either used individual marketing innovations (and to varying degrees of use) or they haven't. The response to each proposition was given a score (e.g., from 5 for strongly agree to 1 for strongly disagree) and each variable was created by averaging the scores for each of the propositions used.

\section{Independent Variable}

The market orientation variable was constructed by asking respondents to answer a set of propositions that measure market orientation. The propositions are taken from the Jaworski and Kohli (1993) construct, which has been widely used by studies on market orientation and was used by Advani and Borins (2001) in their study on airport market orientation. The construct consists of three elements (intelligence generation, intelligence dissemination and intelligence response) and twenty propositions.

Three of the twenty propositions were rejected from this study on the basis that they are not particularly relevant. Two propositions are concerned with end users (i.e., passengers) and this study is only concerned with airlines. A third proposition is concerned with how businesses respond to competitor's price changes and the extent to which airports in EPAs engage in price wars is likely to be limited by the existence of multi-airport groups and a limited degree of autonomy over pricing.

Slight changes were made to the terminology used by Jaworski and Kohli (1993) and this is in line with Harris (2001) who suggests that market orientation constructs should be adapted for different contexts. For instance, the terms 'business unit,' 'customers,' 'products or services,' 'fundamental shifts,' and 'periodically' were replaced with 'airport,' 'airlines,' 'service or facilities,' 'changes,' and 'regu- 
larly.' In addition, references to 'departments' were replaced by references to 'staff' in order to reflect the fact that some airports in EPA's may be so small or flat structured that they do not have formal departments.

The variable created was called MKTOR and the three elements of MKTOR were called MIG (intelligence generation), MID (intelligence dissemination) and MIR (intelligence response). The seventeen propositions used to measure market orientation are listed in Appendix A.

\section{Dependent Variable}

The measures of marketing performance used in this study include three key performance measures: (1) the attraction of new routes; (2) the growth of existing routes; and, (3) the retention of existing routes. In line with previous studies (e.g., Matsuno \& Mentzer, 2000), respondents were asked to rate the performance of their airport in relation to competitors in a particular time period. However, due to the long lead times in the airport industry, a three-year period was used instead of the traditional one-year period. A three-year period has been used in previous studies (e.g., Ellis, 2005) and is normally used in industry's that are slower moving. In addition, the term 'similar or competing airports' was used instead of just 'competing airports' in order to overcome potential confusion from airports that belong to multi-airport groups and may not consider other airports in that group as being competitors. The variable created was called PERF.

\section{Moderating and Mediating Variables}

Characteristics of each of the moderator and mediator variables have already been discussed in this paper and a proposition was developed for each characteristic. For instance, market turbulence is characterised by the rate of change in customers and their needs and preferences (Kohli \& Jaworski, 1990) so a proposition was developed to measure the rate of change in customers and another was developed to measure changes in customer needs and preferences. The variable for environmental support was created by averaging the scores for the propositions used to measure market turbu- lence, competitive intensity, market opportunities and constraints.

The moderator variables were called TURB (market turbulence), COMP (competitive intensity), DEMAND (market opportunities), SUPPLY (constraints) and ENV (environmental support). The mediator variable was called INNO (marketing innovations).

The strategic focus variables (public focus and leisure focus) were not created using propositions. Instead, they were created using two questions, where respondents had to tick one of two categories. An active value of 1 was assigned to airports that ticked that they have focused on developing public (as opposed to commercial) services and leisure (as opposed to traditional) services, during the last three years. The variables created were called PUBFOCUS (public focus) and LEIFOCUS (leisure focus). A base value of 0 was assigned to airports that ticked that they have focused on developing commercial services and traditional services. The variables created were called COMFOCUS (commercial focus) and TRAFOCUS (traditional focus).

\section{Sample and Data Collection}

At the European level, Gloersen (2005) defines EPAs according to their relative inaccessibility to potential markets or separate permanent handicaps (sparse population density, islands or mountain areas). In line with Gloersen, this study included all NUTS II ${ }^{1}$ regions of the European Union and the European Free Trade Association that are relatively inaccessible to potential markets or are sparsely populated, islands or mountain areas. ${ }^{2}$

A population of 214 airports were included in this study on the basis that they are located in EPA's and meet the European Commission's eligibility criteria for airports of common interest (e.g., see European Commission, 1996). Airports in peripheral parts of the countries that joined the European Union in 2004 were not included on the basis that they had only recently joined the deregulated European aviation market. The airports included in this study are mainly concentrated in the Nordic regions, the Highlands and Islands of Scotland, Ireland, and Southern/Mediterranean Europe. 
According to Veal (2006), surveys should be drafted and tested before a final version is designed so a draft survey was developed and discussed with airport managers at the 4th Forum on Air Transport in Remoter Regions. The draft survey was also discussed with academics at the 14th Nordic Symposium in Tourism and Hospitality Research. Two rounds of consultation then followed with a revised version of the draft survey being sent to experts from the field of airport management or market orientation. A final draft version of the survey was then piloted and responses were received from eleven European airports.

The final version of the survey was sent directly to airport managers by email and in order to maximise flexibility, respondents were able to complete the survey by computer and return it by email or they could print it off and return it by post or fax. A hard copy of the survey was sent to any airports for which email addresses were not found. The first mailing of the survey took place on 17th November 2005 and two subsequent mailings took place on 17th February 2006 and 17th March 2006.

Eighty-four airports returned usable surveys resulting in a response rate of $39 \%$. Bias testing indicates that the sample suffers slightly from non-response bias from airports in Southern/ Mediterranean Europe. This is probably a reflection of the fact that the survey was written in English and that English is less widely used in Southern/Mediterranean Europe. Some airport managers passed the survey onto colleagues for completion and it was found that the sample suffers slightly from marketing job-related bias, where responses on market opportunities, marketing innovations and marketing performance were significantly higher from those working in marketing job-related areas. The airports that took part in this study are listed in Appendix B.

\section{FINDINGS}

\section{Reliability Analysis and Construct Validity}

Previous studies on market orientation have tested the reliability and validity of variables (e.g., Hooley et al., 2003; Sin et al., 2005). This study tests the reliability of MKTOR, INNO and PERF in order to check for internal consistency (i.e., whether each individual proposition that is used to construct the variable is measuring the same aspect). None of the moderating variables were tested for reliability because they are constructed from two propositions or one question each and it is recommended that variables constructed from less than three propositions are not tested for reliability (Peter, 1979). This study also tests the convergent validity (i.e., the degree of agreement) between the three different elements of the MKTOR variable (MIG, MID and MIR). None of the other variables were tested for convergent validity, as they are not constructed by different elements, only different propositions.

Churchill (1979) recommends that reliability is tested using Cronbach's coefficient alpha. Responses for each of the propositions for MKTOR, INNO and PERF were correlated with each other using Cronbach's coefficient alpha in order to indicate the level of convergence, which according to Nunnally and Bernstein (1994) should produce an alpha coefficient of above .70. The reliability of each proposition (to the overall measure of each variable) was then tested after omitting each individual proposition. The output for each variable is provided in Table 1.

As can be seen from Table 1, the alpha coefficient for the overall measure of MKTOR, INNO and PERF exceeds the recommended value of $.70(.8917, .8895$ and .8012 respectively), which confirms the reliability of each construct. The alpha coefficient for MKTOR and INNO increases slightly when two propositions (MIRd and INNOa) are deleted. However, the propositions have not been deleted on the basis that their impact is minimal (MKTOR increases from .8917 to .8940 and INNO increases from .8895 to .8959 ).

Spearman's Rho correlation analysis was used to analyse the convergent validity of the three elements of MKTOR (MIG, MID and MIR) and the output is provided in Table 2.

As can be seen from Table 2, correlations among the three elements of MKTOR are fairly high (coefficients range from .648 to .740) and each correlation is significant $(\mathrm{p}<.01)$. In addition, each of the three elements is highly correlated to the overall MKTOR construct (coefficients range from .861 to .928) and each 
TABLE 1. Reliability of MKTOR, INNO and PERF

\begin{tabular}{|l|l|l|l|l|l|l|l|l|l|l|}
\hline Proposition & Alpha & $\begin{array}{l}\text { Alpha if } \\
\text { deleted }\end{array}$ & Proposition & Alpha & $\begin{array}{l}\text { Alpha if } \\
\text { deleted }\end{array}$ & Proposition & Alpha & $\begin{array}{l}\text { Alpha if } \\
\text { deleted }\end{array}$ \\
\hline MKTOR & .8917 & & & INNO & .8895 & & & PERF & .8012 & \\
\hline MIGa & & .8857 & & INNOa & & .8959 & & PERFa & & .7344 \\
\hline MIGb & & .8844 & & INNOb & & .8816 & & PERFb & & .7397 \\
\hline MIGc & & .8829 & & INNOc & & .8680 & & PERFc & & .7149 \\
\hline MIGd & & .8885 & & INNOd & & .8687 & & & & \\
\hline MIGe & & .8790 & & INNOe & & .8893 & & & & \\
\hline MIDa & & .8819 & & INNOf & & .8723 & & & & \\
\hline MIDb & & .8825 & & INNOg & & .8797 & & & & \\
\hline MIDc & & .8914 & & INNOh & & .8677 & & & & \\
\hline MIDd & & .8880 & & INNOi & & .8845 & & & & \\
\hline MIDe & & .8875 & & INNOj & & .8752 & & & & \\
\hline MIRa & & .8838 & & & & & & & & \\
\hline MIRb & & .8790 & & & & & & & & \\
\hline MIRc & & .8837 & & & & & & & & \\
\hline MIRd & & .8940 & & & & & & & & \\
\hline MIRe & & .8883 & & & & & & & & \\
\hline MIRf & & .8895 & & & & & & & & \\
\hline MIRg & & .8848 & & & & & & & & \\
\hline
\end{tabular}

TABLE 2. Convergent Validity of MKTOR

\begin{tabular}{|l|l|c|c|c|c|}
\hline & & MIG & MID & MIR & MKTOR \\
\hline MIG & Coefficient & 1.000 & $.648^{\star *}$ & $.740^{\star *}$ & $.877^{\star *}$ \\
\hline & Significance (2-tailed) &. & .000 & .000 & .000 \\
\hline MID & Coefficient & $.648^{\star *}$ & 1.000 & $.705^{\star *}$ & $.861^{\star *}$ \\
\hline & Significance (2-tailed) & .000 &. & .000 & .000 \\
\hline MIR & Coefficient & $.740^{\star *}$ & $.705^{\star *}$ & 1.000 & $.928^{\star *}$ \\
\hline & Significance (2-tailed) & .000 & .000 &. & .000 \\
\hline
\end{tabular}

${ }^{\star *}$ Correlation is significant at the .01 level (2-tailed).

correlation is significant $(\mathrm{p}<.01)$. The pattern of correlations confirms the convergent validity of MKTOR.

\section{Direct Effect}

Spearman's Rho correlation analysis between MKTOR and PERF was used to test H1. The analysis indicates the existence of a moderate and significant relationship between MKTOR and PERF (coefficient of .449 and $\mathrm{p}<.01$, 2-tailed). This indicates that higher levels of MKTOR result in higher levels of PERF and means that $\mathrm{H} 1$ can be accepted. A certain degree of caution needs to be taken when accepting such a hypothesis because correlation analysis only demonstrates whether or not a significant relationship exists between two variables. It does not control for other variables and does not test for causality (i.e., the extent to which a particular variable can predict performance). Marketing literature (e.g., Kotler, 2005) suggests that environmental and market-level factors may affect performance and previous studies on market orientation (e.g., Narver \& Slater, 1990) suggest that they must be controlled when analysing the effect of market orientation on performance.

Further analysis was provided using stepwise regression analysis in order to investigate the 
impact of MKTOR on PERF, controlling for TURB, COMP, DEMAND and SUPPLY. The output is provided in Table 3.

As can be seen from Table 3,39\% of the variance in PERF can be accounted for by DEMAND and MKTOR (R-square $=.392$ ). The analysis also shows that DEMAND has the greatest impact on PERF (coefficient of .336 and $p<.01$ ). The impact of MKTOR on PERF is slightly less than that of DEMAND and the impact is also less significant (coefficient of .274 and $\mathrm{p}<.05)$.

\section{Moderating Effect}

Baron and Kenny (1986) suggest that a standard Two-Way ANOVA test can be used to test for moderation when both the independent variable and the moderator are dichotomous. The key test for moderation is that the interaction term between the independent variable and the moderator is significant.

The variables SERFOCUS and AIRFOCUS were already dichotomous. An active value of 1 was assigned to airports with a public focus (PUBFOCUS) and a leisure focus (LEIFOCUS). $A$ base value of 0 was assigned to airports with a commercial focus (COMFOCUS) and a traditional focus (TRAFOCUS). All other variables had to be re-coded.
MKTOR, TURB, COMP, DEMAND and SUPPLY were dichotomised between those that on average, agreed with the relevant propositions and those that did not. The former was assigned an active value of 1 and the latter was assigned a base value of 0 . The active value of each variable was labelled 'high' whilst the base value was labelled 'low.'

Table 4 provides the interaction output of the Two-Way ANOVA test for each variable.

As can be seen from Table 4, two of the variables demonstrate significant interaction terms. These are TURB $(\mathrm{p}<.05)$ and AIRFOCUS $(\mathrm{p}<$ $.05)$. This signals the presence of an interaction but it does not test the hypotheses. These can be tested by taking the analysis a stage further and investigating what effect the moderator has on the nature of the relationship between market orientation and performance. This was achieved using Simple Slope analysis (i.e., the plotting of graphs that indicate the relationship between MKTOR and PERF at different values of the moderator). Single Slope analysis with TURB and AIRFOCUS as the moderators can be seen in Figure 1.

As can be seen in Figure 1, when the moderator is high (e.g., high TURB and LEIFOCUS) the relationship between MKTOR and PERF is strong and positive. This is indicated by the slope of the line. When the moderator is low

TABLE 3. Controlled Stepwise Regression for MKTOR on PERF

\begin{tabular}{|l|c|c|}
\hline \multirow{2}{*}{ Variables } & \multicolumn{2}{|c|}{ Regression values } \\
\cline { 2 - 3 } & Coefficients & P-value \\
\hline Intercept & 1.101 & .030 \\
\hline DEMAND & .336 & .000 \\
\hline MKTOR & .274 & .041 \\
\hline
\end{tabular}

a. Dependent variable: PERF.

R-square $=.392$.

TABLE 4. Two-Way ANOVA Test for Moderation

\begin{tabular}{|l|r|}
\hline Independent variable/moderator & \multicolumn{1}{|c|}{ Significance } \\
\hline MKTOR/TURB & .044 \\
\hline MKTOR/COMP & .908 \\
\hline MKTOR/SERFOCUS & .447 \\
\hline MKTOR/AIRFOCUS & .041 \\
\hline MKTOR/DEMAND & .446 \\
\hline MKTOR/SUPPLY & .780 \\
\hline
\end{tabular}

a. Dependent variable: PERF. 
FIGURE 1. Single Slope Analysis

TURB as the moderator

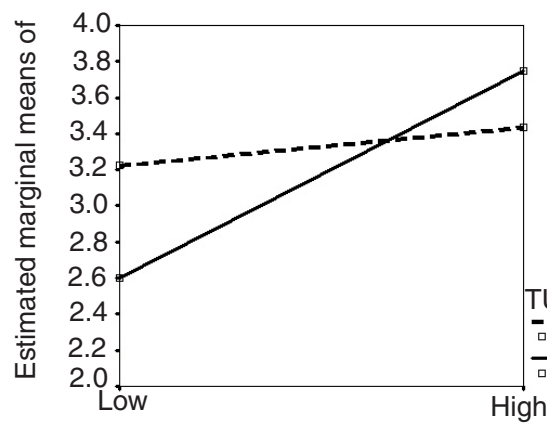

MKTOR
AIRFOCUS as the moderator

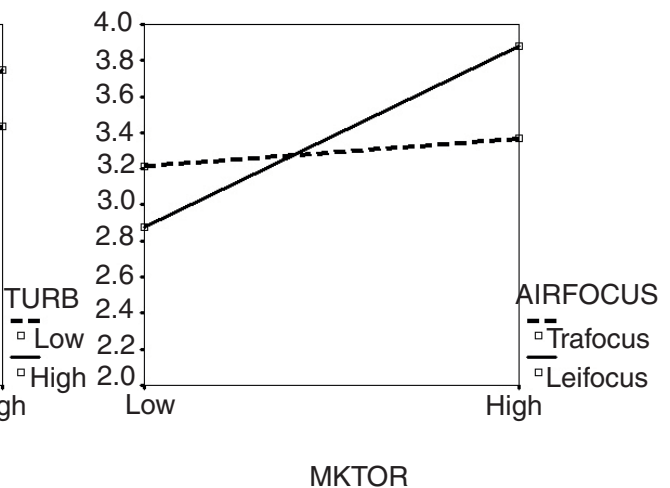

(e.g., low TURB and TRAFOCUS) there is very little relationship between MKTOR and PERF. Therefore both $\mathrm{H} 2$ and $\mathrm{H} 5$ can be accepted. None of the other interaction terms returned significant values during the Two-Way ANOVA test for moderation so $\mathrm{H} 3, \mathrm{H} 4, \mathrm{H} 6$ and H7 can be rejected.

\section{Mediating Effect}

Mediation testing is an area where there is some agreement about the broad principles involved but some argument about the details. However, this study will follow the procedure that is recommended by Baron and Kenny (1986). They suggest that for the mediator to be a mediator of the relationship between the independent variable and the dependent variable, three conditions must be met.

1. The independent variable must significantly predict the dependent variable. If not, there is no relationship to mediate.

2. The independent variable must significantly predict the mediator.

3. The mediator must significantly predict the dependent variable after controlling for the independent variable.

This means that if by adding the mediator to the prediction of the dependant variable from the independent variable in a regression model, the effect of the independent variable falls close to zero, a complete mediation can be assumed.
If the effect of introducing the mediator is to reduce the effect of the independent variable by a non-trivial amount but not to zero, a partial mediation can be assumed. If the effect of the independent variable is not reduced after the introduction of the mediator, there is no mediation.

The three conditions for $\mathrm{H} 8$ were tested using three separate regressions. The output is provided in Table 5.

As can be seen from Table 5, the three conditions have been met. After adding the mediator to the prediction of the dependant variable from the independent variable in regression 3 , the effect of the independent variable falls close to zero (.040) so a partial mediation can be assumed. This result means that $\mathrm{H} 8$ can be accepted.

H9 was tested using a Two-Way ANOVA analysis. The interaction term of the independent variable (INNO) and the moderator (ENV) was not significant $(\mathrm{p}=.508)$ so $\mathrm{H} 9$ can be rejected.

\section{DISCUSSION}

\section{Main Findings}

The findings of this study confirm the reliability and validity of the Jaworski and Kohli (1993) construct and support Advani and Borins (2001) in its application to the airport industry. 
TABLE 5. Regression for the Mediating Effect of INNO on MKTOR and PERF

\begin{tabular}{|l|l|l|l|}
\hline & \multicolumn{1}{|c|}{ Unstandardised coefficients } & \multicolumn{2}{c}{ Significance } \\
\hline & \multicolumn{1}{|c|}{ B } & \multicolumn{2}{c}{ Standard error } \\
\hline Regression 1 (PERF as the dependent variable) & 1.337 & .583 & .025 \\
\hline Constant & .523 & .144 & .001 \\
\hline MKTOR & -.219 & .456 & .632 \\
\hline Regression 2 (INNO as the dependent variable) & .113 & .000 \\
\hline Constant & .747 & \multicolumn{2}{l}{} \\
\hline MKTOR & .514 & .005 \\
\hline Regression 3 (PERF as the dependent variable) & .163 & .803 \\
\hline Constant & 1.480 & .135 & .000 \\
\hline MKTOR & .040 & .645 & \\
\hline INNO &
\end{tabular}

A moderate and positive relationship was found to exist between market orientation and performance and the relationship is significant. This means that the greater the market orientation of an airport, the greater its performance. The relationship between market orientation and performance has never been tested in an airport context so the finding is somewhat unique. However, it does support studies on other industries and cultures that have confirmed a positive and significant relationship between market orientation and marketing performance (e.g., Hooley et al., 2003; Sin et al., 2005).

Further analysis was used to test for causality and the analysis controlled for the impact of environmental and market-level factors. In line with Narver and Slater (1990), the findings of this study show that the relationship between market orientation and performance is causal (i.e., that market orientation does have a direct effect on performance). This study also finds that the effect of market opportunities (i.e., market growth and potential) on performance is causal and is much stronger than that of market orientation. This only reinforces the need for airports to adopt market orientated management practices. This is because market orientated airports are likely to have superior market sensing and customer linking capabilities that enable them to stimulate market growth or take advantage of any potential opportunities.

Only two factors (market turbulence and a focus on developing leisure services) were found to have a significant moderating effect on the relationship between market orientation and performance and the effect of these factors is positive. This means that the relationship between market orientation and performance is strong when market turbulence is high and when airports are focused on developing leisure services.

The finding that market turbulence has a significant and positive effect supports the findings of previous studies (e.g., Harris, 2001; $\mathrm{Kim}, 2003$ ). The finding that a focus on developing leisure services has a significant and positive effect cannot be compared to previous studies as strategic focus has never been investigated before in this context (it is usually investigated in the context of whether a company is pursuing a low-cost, differentiation or focus strategy).

Airport marketing innovations were found to have a positive mediating effect on the relationship between market orientation and performance. This supports the findings of previous studies (e.g., Agarwal et al., 2003; Han et al., 1998) and means that market orientation has a positive effect on performance because airports are more likely to be innovative in their approach to airport marketing.

Further analysis investigated whether an innovation-friendly environment can moderate the relationship between marketing innovations and performance. Contrary to Gray et al. (2000), the findings of this study provide no evidence to suggest that the relationship between innovation and performance is moderated by an innovation-friendly environment and therefore implies that innovative marketing practices 
should be adopted by airports, irrespective of the nature of their environmental or marketlevel conditions.

\section{Managerial Implications}

The findings of this study have a number of implications for managers of airports in EPAs. In particular, they suggest that airports wishing to outperform similar or competing airports can do so by adopting a market orientation and should therefore seek to continually monitor and improve the way in which they gather, disseminate and respond to market intelligence. The seventeen propositions that have been developed for this study as a measure of market orientation can be used as a diagnostic tool to identify areas where airport market orientation is weak and where specific improvements are needed.

Market opportunities have the greatest effect on performance and can be influenced by a market orientation. However, simply engaging in market orientated activities does not ensure that the desired consequences of those activities will be met. For instance, the quality of market intelligence that is gathered and disseminated may be questionable or the response to market intelligence may be inappropriate. Human resource departments can reduce the margin for error by identifying the key skills and management competencies that are required to implement a market orientation and develop training programmes to improve the organisation-wide understanding of the activities involved in developing a market orientation. Senior managers can then try to develop a corporate culture that reinforces behaviours that are consistent with market orientation.

The relationship between market orientation and performance is particularly strong when market turbulence is high and when airports are focused on developing leisure services. This is not likely to affect all airports in EPAs. However, for airports that do operate in turbulent markets and/or focus on developing leisure services, the development of a market orientation is important and is likely to enhance their ability to attract new routes and grow and retain existing routes.

Market orientation has a positive effect on performance because airports are more likely to be innovative in their approach to marketing and this is irrespective of whether or not airports operate in an innovation-friendly environment. Airports can use the market orientation construct to develop relevant and effective marketing innovations and should develop a corporate culture that emphasises an innovative approach to marketing. This calls for the need to invest in marketing-related airport activities with appropriate financial and human resources. Airports should monitor and assess the effectiveness of additional resources or the implementation of different marketing innovations.

\section{Recommendations for Future Research}

This study has produced a number of relevant and interesting insights into the relationship between market orientation and the performance of airports in EPAs. However, a number of limitations exist and it is important to recognise the limitations and to make recommendations for future research.

Firstly, the population for this study consists of airports in EPAs and means that the findings of this study are limited to those airports. Future studies on the relationship between market orientation and airport performance could be conducted on a Europe-wide sample of airports so see if the effect at airports in EPAs is any different to those in more centrally located areas.

Secondly, surveys were sent to the airport manager, which means that data for this study was sought from key airport personnel. Future studies on airport market orientation could use multiple informants in order to test the reliability and validity of the data. Future studies should also control for marketing job-related bias as this affected the responses in this study.

Thirdly, cross sectional data was used in this study so the findings only provide an analysis of the current situation. This means that whilst the findings lend support to the existence of a prior relationship, the extent to which they provide evidence of a causal relationship is limited. A time-series testing of airport market orientation could be carried out in the future so that causation can be investigated. In addition, testing for differences between airports that still operate in a regulated environment versus those that operate in a deregulated environment would allow 
for a comparison to be made between the effects of market orientation in different regulatory environments.

Fourthly, all of the variables used in this study were created using a survey with similar measures (i.e., responses to propositions using 4- or 5-point Likert scales). The fact that measures were obtained at the same time using similar procedures may have exaggerated the strength of some of the relationships. Mixed methods of data collection could be used by future studies on airport market orientation in order to reduce this limitation.

Finally, all of the variables used in this study were created from the perceptions of the respondents. Future studies on airport market orientation could use absolute measures, as these would provide more accurate and meaningful findings. However, respondents may not know the answers to the questions and may not be willing to divulge such information.

\section{NOTES}

1. In order to collect and compare data on different states and their regions, Eurostat have defined a Nomenclature of Territorial Units for Statistics (NUTS), which is based primarily on the institutional divisions of states at different levels. The present NUTS system divides the countries of Europe into five levels (three regional and two local), known as NUTS I through NUTS V.

2. Data and methodology for identifying EPA's was provided by two different sources: (1) Schürmann and Talaat (2000) for inaccessible and sparsely populated regions and mountain areas; and (2) Plainstat Europe \& Bradley Dunbar Associates (2003) for islands.

\section{REFERENCES}

Advani, A., \& Borins, S. (2001). Managing airports: A test of the new public management. International Public Management Journal, 4(1), 91-107.

Agarwal, S., Erramilli, M. K., \& Dev, C. S. (2003). Market orientation and performance in service firms: Role of innovation. Journal of Services Marketing, 17(1), 68-82.

Baron, R. M., \& Kenny, D. A. (1986). The moderator-mediator variable distinction in social psychological research: Conceptual, strategic, and statistical considerations. Journal of Personality and Social Psychology, 51(6), 1173-1182.

Carrara, D. (2005, February). Aberdeen Airport. Airliner World, pp. 28-31.
Churchill, G. A. (1979). A paradigm for developing better measures of marketing constructs. Journal of Marketing Research, 16(1), 64-73.

Day, G. S. (1994). The capabilities of market driven organisations. Journal of Marketing, 58(4), 37-52.

Deshpandé, R., Farley, J. U., \& Webster, F. E., Jr. (1993). Corporate culture, customer orientation and innovativeness in Japanese firms: A quadrad analyses. Journal of Marketing, 57(1), 23-37.

Ellis, P. D. (2005). Market orientation and marketing practice in a developing economy. European Journal of Marketing, 39(5/6), 629-645.

European Commission. (1996). Decision no. 1692/96/ EC of the European Parliament and of the Council of 23rd July 1996 on Community guidelines for the development of the Trans-European Transport Network (Official Journal L228, 09/09/1996 P.00010104). Brussels: Author.

Gloersen, E. (2005). The importance of airports in securing accessibility and the role of demographics. Paper presented at the 4th Forum on Air Transport in Remoter Regions, Stockholm, Sweden.

Graham, A. (2003). Managing airports: An international perspective (2nd ed.). Oxford: ButterworthHeinemann.

Gray, B. J., Matear, S. M., \& Matheson, P. K. (2000). Improving the performance of hospitality firms. International Journal of Contemporary Hospitality Management, 12(3), 149-155.

Halpern, N. (2006). Marketing of airports for tourism: Exploiting northern potential. Paper presented at the 14th Nordic Symposium in Tourism and Hospitality Research, Akureyri, Iceland.

Han, J. K., Kim, N., \& Srivastava, R. K. (1998). Market orientation and organisational performance: Is innovation a missing link? Journal of Marketing, 62(4), $30-45$.

Harris, L. C. (2001). Market orientation and performance: Objective and subjective empirical evidence from UK companies. Journal of Management Studies, 38(1), 17-43.

Hooley, G., Fahy, J., Greenley, G., Beracs, J., Fonfara, K., \& Snoj, B. (2003). Market orientation in the service sector of the transition economies of central Europe. European Journal of Marketing, 37(1/2), 86-106.

Jaworski, B. J., \& Kohli, A. K. (1993). Market orientation: Antecedents and consequences. Journal of Marketing, 57(3), 53-70.

Kealey, S. (2004, November). Route partnerships in action. Airline Business, p. 82.

Kim, Y. (2003). How will market orientation and environment and company's character influence performance? Cross Cultural Management: An International Journal, 10(4), 71-88.

Kohli, A. K., \& Jaworski, B. J. (1990). Market orientation: The construct, research propositions, and managerial implications. Journal of Marketing, 54(2), 1-18.

Kotler, P. (2005). Marketing management (12th ed.). Englewood Cliffs, NJ: Prentice-Hall. 
Matsuno, K., \& Mentzer, J. T. (2000). The effects of strategy type on the market orientation-performance relationship. Journal of Marketing, 64(4), 1-16.

Matsuno, K., Mentzer, J. T., \& Rentz, J. O. (2005). A conceptual and empirical comparison of three market orientation scales. Journal of Business Research, 58(1), 1-8.

Narver, J. C., \& Slater, S. F. (1990). The effect of a market orientation on business profitability. Journal of Marketing, 54(4), 20-35.

Nunnally, J., \& Bernstein, I. (1994). Psychometric theory (3rd ed.). London: McGraw-Hill.

Peter, J. P. (1979). Reliability: A review of psychometric basics and recent marketing practices. Journal of Marketing Research, 16(1), 6-17.

Plainstat Europe \& Bradley Dunbar Associates. (2003). Analysis of the island regions and outermost regions of the European Union: Part 1: The island regions and territories (European Commission Contract Number 2000.CE.16.0.AT.118). Brussels: European Commission.

Schürmann, C., \& Talaat, A. (2000). Towards a European peripherality index-final report. Report for General Directorate XVI (Regional Policy) of the European Commission, Dortmund: Institute of Spatial Planning.

Sin, L. Y. M., Tse, A. C. B., Heung, V. C. S., \& Yim, F. H. K. (2005). An analysis of the relationship between mar- ket orientation and business performance in the hotel industry. Hospitality Management, 24(4), 555-577.

Slater, S. F., \& Narver, J. C. (1994). Does competitive environment moderate the market orientation-performance relationship? Journal of Marketing, 58(1), 46-55.

Veal, A. J. (2006). Research methods for leisure and tourism: A practical guide (3rd ed.). Harlow: Prentice Hall.

Williams, G. (2002). Airline competition: Deregulation's mixed legacy. Aldershot: Ashgate.

Williams, G., \& Pagliari, R. (2004). A comparative analysis of the application and use of public service obligations in air transport within the EU. Transport Policy, 11(1), 55-66.

Wu, J.-J. (2004). Influence of market orientation and strategy on travel industry performance: An empirical study of e-commerce in Taiwan. Tourism Management, 25(3), 357-365.

SUBMITTED: October 4, 2006 FINAL REVISION SUBMITTED:

December 15, 2006

ACCEPTED: December 28, 2006 REFEREED ANONYMOUSLY

doi:10.1300/J073v24n01_04 


\section{APPENDIX A \\ Items Used to Measure Market Orientation}

Intelligence generation

1. We meet airlines at least annually to discuss their future needs.

2. We conduct a lot of 'in-house' market research.

3. We are slow to identify changes in the preferences of our airlines.

4. We are slow to identify major changes in our industry (e.g., technology).

5. We regularly monitor the likely effect of changes in the business environment (e.g., travel trends and the economy) on our airlines.

Intelligence dissemination

6. Managers meet at least 4 times a year to discuss market trends and developments.

7. Managers spend time discussing the future needs of our airlines.

8. High levels of communication are maintained between managers and other staff.

9. Staff at all levels are quick to find out when something important happens to one of our main airline customers.

10. Managers tend to be slow in alerting other managers of important changes in the business environment.

Intelligence response

11. We review service standards at least annually to ensure that they are in line with what our airlines expect.

12. Managers meet at least 4 times a year to plan a response to changes taking place in our business environment.

13. Even if we came up with a great marketing plan, we would probably be slow to implement it.

14. When we find out that our airlines would like us to modify an aspect of our service or facilities, we make a determined effort to do so.

15. For one reason or another, we tend to ignore changes in the needs of our airlines.

16. The activities of different staff are well co-ordinated.

17. We would respond quickly if a competitor targeted one of our airlines.

\section{APPENDIX B \\ Airports that Took Part in this Study}

Aberdeen; Akureyri; Ålesund; Andøya; Araxos; Båtsfjord; Belfast City; Benbecula; Bergen; Bodø; Bornholm; Chania; Cork; Dublin; Faro; Friedrichshafen; Galway; Gibraltar; Göteborg City; Göteborg; Landvetter; Grenoble; Guernsey; Halmstad; Harstad; Ibiza; Inverness; Ioannina; Islay; Jersey; Jönköping; Jyväskylä; Kavala; Kefallinia; Keflavik; Kerry; Kirkenes; Kos; Kramfors; Kristiansand; Kristianstad; Kristiansund; Kuusamo; Lakselv; Limnos; Linköping City; Luleå; Menorca; Mo i Rana;

Mora; Norrköping; Olbia; Östersund; Oulu; Pajala; Rhodos; Rodez; Ronneby; Røros; Røst; Salzburg; Santander; Seinæjoki; Shannon; Sion; Sitia; Sligo; St Mary's; Stokmarknes; Stornoway; Sumburgh; Svalbard; Sveg; Tiree; Trollhättan; Tromsø; Trondheim; Vadsø; Væsterås; Vardø; Växjö; Waterford; Wick; Zakinthos; Zaragoza. 